\title{
Intravenous sedation accompanied with fentanyl is effective for intramaxillary fixation in trauma patients
}

\author{
Kentaro Ouchi* \\ Department of Dental Anesthesiology, Field of Maxillofacial Diagnostic and Surgical Sciences, Faculty of Dental Science, Kyushu University Graduate School, Japan
}

\begin{abstract}
Operation of intramaxillary fixation that is required treatment of jaw fracture require long operation time, where intravenous sedation is adaptable to operation of intramaxillary fixation. Four cases were performed anesthesia and systemic management by author anesthesiologists. Anesthesia record was studied about adverse event (body movement, hemodynamic changes and pain complaint) in each case. Four patients classed in ASA physical status I. In intravenous sedation case using sedative or pentazocine combining sedative, hemodynamic changes and body movement were observed during operation. In intravenous sedation or systemic management cases of using fentanyl, body movement and hemodynamics changes were not observed during operation. Glossoptosis and hypopnea were not observed in four cases.

The sedation is inhibited, if pain control is insufficient. The pain control using local anesthetic is difficult for pain of intramaxillary fixation operation. Fentanyl, specialized analgesic by high selectivity with $\mu$ receptor, is useful for operation of intramaxillary fixation, because local anesthetic is not provided enough analgesia.

In conclusion, in intravenous sedation for intramaxillary fixation operation, the full agonist opioid such as the fentanyl, specialized in analgesia, is useful to provide enough analgesia.
\end{abstract}

\section{Introduction}

Intravenous sedation is widely used effectively for oral surgery and dental procedure [1-7]. Dental anxiety, stress and pain can lead to hemodynamic changes such as hypertension or increased heart rate. Operation of intramaxillary fixation that is required treatment of jaw fracture require long operation time, where intravenous sedation is adaptable to operation of intramaxillary fixation. Anesthesia management for operation of intramaxillary fixation is not reported.

The purpose of the present study was to determine whether intravenous sedation and systemic management during intramaxillary fixation contributed to pain control and hemodynamics stabilization.

\section{Patient and method}

Anesthesiologist certified by the Japanese Board of Dental Anesthesiologists performed four cases of anesthesia and systemic management for intramaxillary fixation operation. Anesthesia record was studied about adverse event (body movement, hemodynamic changes and pain complaint) in each case. The hemodynamic changes were defined as increase of $20 \%$ in systolic blood pressure (SBP), diastolic blood pressure (DBP) or heart rate (HR), comparison with the baseline.

\section{Results}

Four patients classed in ASA physical status I. Hemodynamic changes and intraoperative body movement were observed in case 1 and 2 . In case 1 , only sedative was used. In case 2 , sedative and pentazocine were used combined. Hemodynamic changes and intraoperative body movement were not observed in case 3 and 4 . In case 3 and 4, fentanyl was used. Glossoptosis and hypopnea were not observed in all cases.
Table 1 shows the hemodynamic changes. In case 1, hemodynamic changes were observed 2 times. In case 2, hemodynamic changes were observed 9 times. In case 3 and 4, hemodynamic changes were not observed. Summaries of 4 cases of the anesthesia management for intramaxillary fixation operation were presented as follows.

\section{Case 1}

A 24-year-old man, $169 \mathrm{~cm}$ in height, weighing $78 \mathrm{~kg}$, was introduced to our hospital two days after injury with complaints of abnormal occlusion and mandibular pain. He hit chin by sports. Median fracture of mandible was diagnosed by computerized tomography (CT) scan and panoramic radiography. Mild trismus, $30 \mathrm{~mm}$ of mouth opening amount was observed. He was classed in ASA physical status I.

Figure 1 shows anesthesia record. On the day after visited to our hospital, intramaxillary fixation was performed under intravenous anesthesia sedation. Intravenous sedation was performed with midazolam 5mg, keeping sedation state of Mackenzie Grant 4. Operation of intramaxillary fixation was started using local anesthesia. Operation was discontinued, because patient's body movement and complaints of pain were observed (sedation state decreased again to 2). Therefore, midazolam administration and local anesthetic injection

Correspondence to: Dr. Kentaro Ouchi, Department of Dental Anesthesiology, Field of Maxillofacial Diagnostic and Surgical Sciences, Faculty of Dental Science, Kyushu University Graduate School, Japan, Tel: +81-92-641-1151; Fax: +81-92-642-6481; E-mail: ken2006anes@yahoo.co.jp

Key words: intramaxillary fixation for jaw fracture, fentanyl, anesthesia management, intravenous sedation based on balanced anesthesia

Received: April 02, 2016; Accepted: April 22, 2016; Published: April 25, 2016 
Table 1. The number of times of hemodynamic changes.

\begin{tabular}{|c|c|c|c|c|}
\hline Case & Using drug & The dose of local anesthetic (ml) & $\begin{array}{c}\text { The number of times that blood } \\
\text { pressure changed }\end{array}$ & $\begin{array}{c}\text { The number of times that heart rate } \\
\text { changed }\end{array}$ \\
\hline Case 1 & Midazolam and pentazocine & 19.8 & 2 & 0 \\
\hline Case 2 & Diazepam and midazolam & 18 & 5 & 4 \\
\hline Case 3 & Fentanyl & 11.7 & 0 & 0 \\
\hline Case 4 & Diazepam, midazolam and fentanyl & 11.2 & 0 & 0 \\
\hline
\end{tabular}

Local anesthetic: $2 \%$ lidocaine containing 12.5 -ppm (1:80000) adrenaline

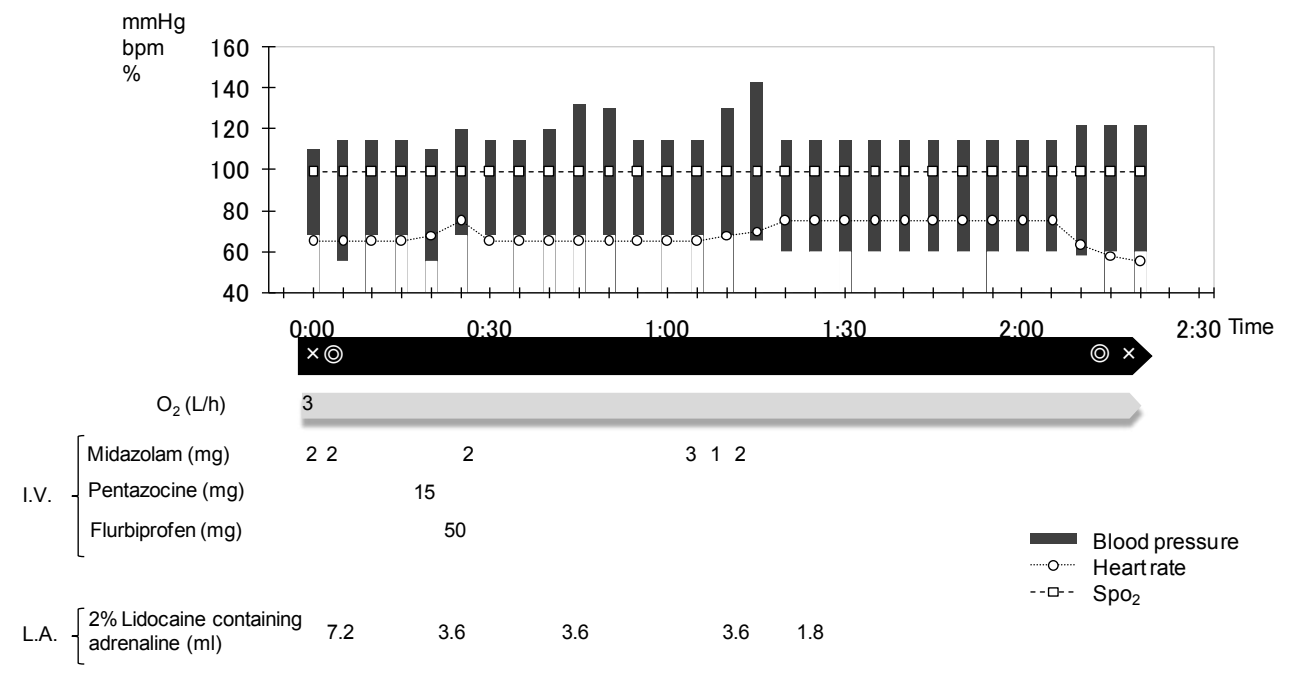

Figure 1. Anesthesia record in case 1

$\times$ : Anesthesia start/finish, (O): Operation start/finish, I.V.: Intravenous administration

L.A.: Local anesthesia, Anesthesia time: 2 hours 30 minutes, Operation time 2 hours 15 minutes.

were added. Operation was restarted when sedative state recovered to 4. But, operation was discontinued, because patient's body movement and complaints of pain were observed again (then sedation state decreased again to 2 ). Therefore, pentazocine $15 \mathrm{mg}$ was administrated, and local anesthetic injection was added. But, body movement restraint became more difficult because insufficient analgesia and excessive sedation with sedative state 5 . Therefore, operation was restarted when sedative state showed 4. During the intraoperative period, operation was discontinued repeatedly and added local anesthetic injection, because patient's body movement occurred whenever ligated wire.

\section{Case 2}

A 36-year-old man, $165 \mathrm{~cm}$ in height, weighing $56 \mathrm{~kg}$, was introduced to our hospital 14 days after injury with complaints of abnormal occlusion and mandibular pain. He hit the lower jaw by fall from a bicycle. Right side mandibular fracture and left mandibular condyle fracture were diagnosed by CT scan and panoramic radiography. Mouth opening amount was observed 40-mm. Abnormal occlusion and deviation of jaw opening pathway were observed. He was classed in ASA physical status I.

Figure 2 shows anesthesia record. On the day after visited to our hospital, intramaxillary fixation was performed under intravenous anesthesia sedation. Intravenous sedation was performed with diazepam $10 \mathrm{mg}$ and midazolam $4 \mathrm{mg}$, keeping sedation state of Mackenzie Grant 4. Operation of intramaxillary fixation was started using local anesthesia. Operation was discontinued, because patient's body movement and complaints of pain were observed (sedation state decreased again to 2). Therefore, diazepam administration and local anesthetic injection were added. Operation was restarted when sedative state recovered to 4 . During the intraoperative period, operation was discontinued repeatedly and added local anesthetic injection, because patient's body movement occurred whenever ligated wire.

\section{Case 3}

A 47-year-old man, $178 \mathrm{~cm}$ in height, weighing $77 \mathrm{~kg}$, was introduced to our hospital the day after injury with complaints of abnormal occlusion and mandibular pain. He hit the lower jaw by falling down on the road. Right side mandibular fracture and left mandibular angle fracture were diagnosed by CT scan and panoramic radiography. Mild trismus, $30 \mathrm{~mm}$ of mouth opening amount was observed. He was classed in ASA physical status I.

Figure 3 shows anesthesia record. On the day after visited to our hospital, intramaxillary fixation was performed under systemic management (mainly pain management). Systemic management was performed with fentanyl. Operation of intramaxillary fixation was started using local anesthesia. During the intraoperative period, fentanyl administration was added appropriately; patient's body movement and complaints of pain were not observed.

\section{Case 4}

A 29-year-old man, $170 \mathrm{~cm}$ in height, weighing $58 \mathrm{~kg}$, was introduced to our hospital the day after injury with complaints of trismus and mandibular pain. He hit the lower jaw by road traffic accident. Median mandibular fracture and left mandibular condyle fracture were diagnosed by CT scan and panoramic radiography. Mild 


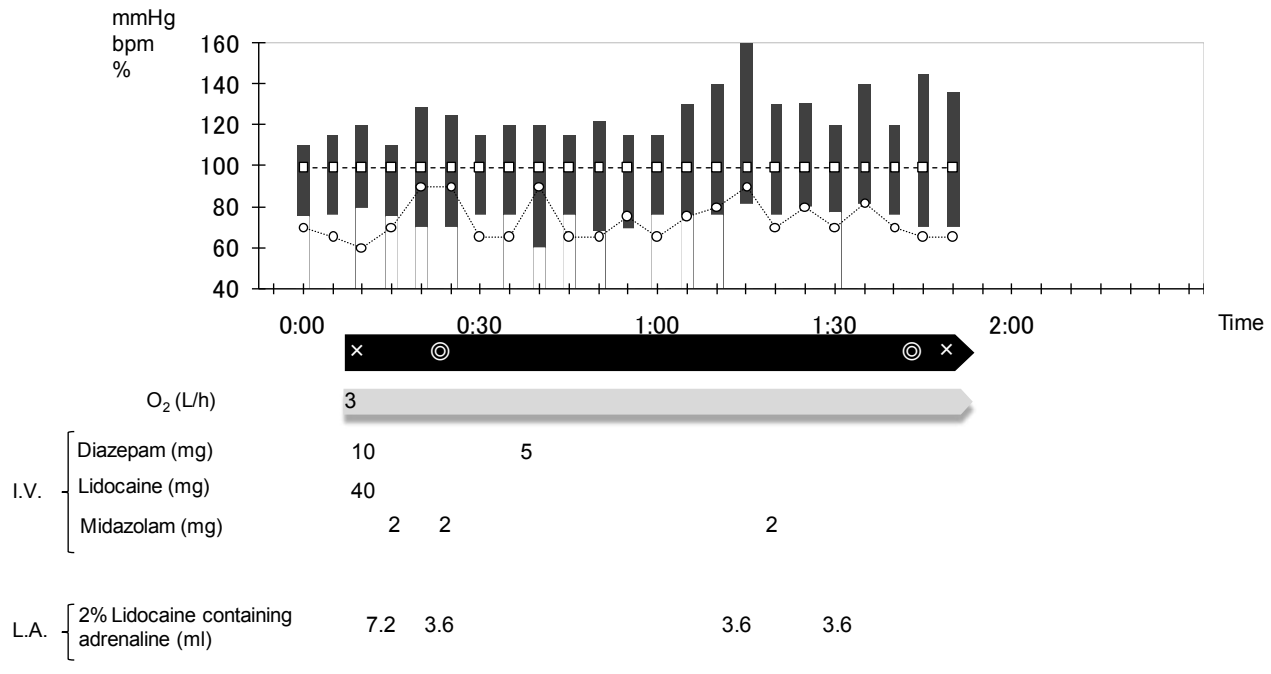

Figure 2. Anesthesia record in case 2

Anesthesia time: 1 hour 40 minutes, Operation time 1 hour 20 minutes.

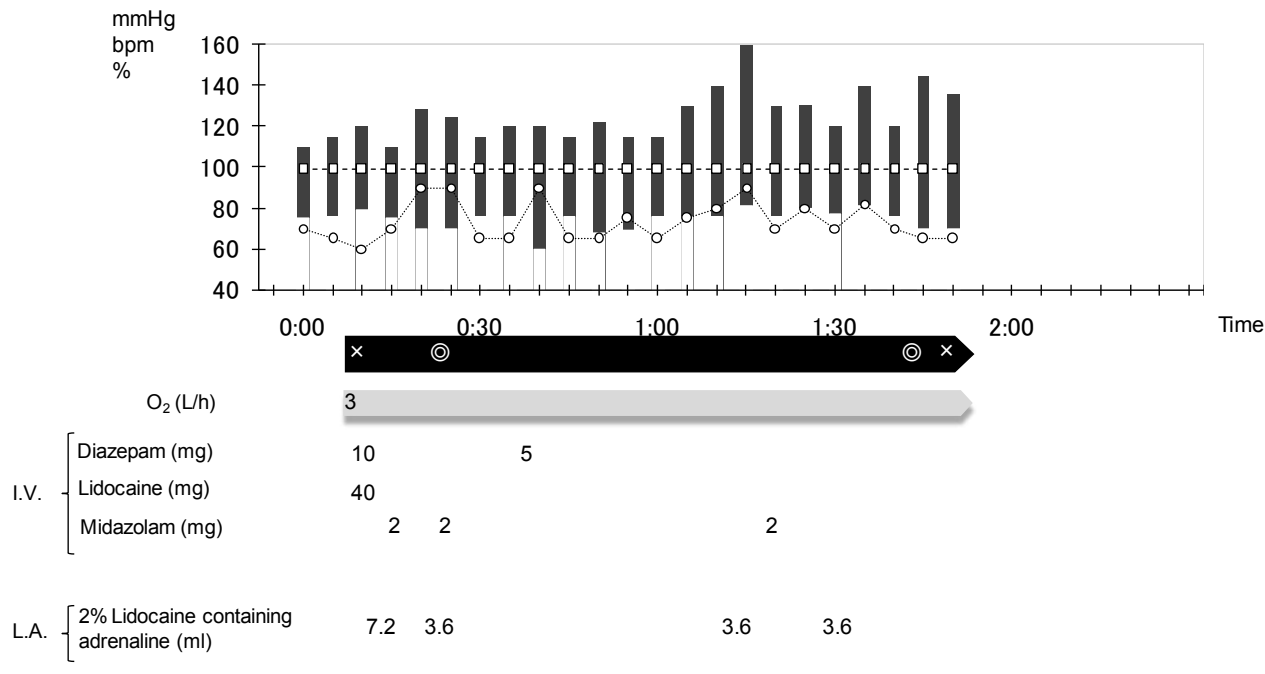

Figure 3. Anesthesia record in case 3

Anesthesia time: 1 hour 43 minutes, Operation time 1 hour 14 minutes.

trismus, $25 \mathrm{~mm}$ of mouth opening amount was observed. He was classed in ASA physical status I.

Figure 4 shows anesthesia record. On the day after visited to our hospital, intramaxillary fixation was performed under intravenous anesthesia sedation. Intravenous sedation was performed with nitrous oxide $30 \%$ and diazepam $10 \mathrm{mg}$ keeping sedation state of Mackenzie Grant 4. Operation of intramaxillary fixation was started using local anesthesia. During the intraoperative period, fentanyl and midazolam administration were added appropriately, keeping sedation state of Mackenzie Grant 3-4, patient's body movement and complaints of pain were not observed.

In all case, the postoperative course was uneventful. On the day after intramaxillary fixation, intermaxillary fixation was performed. All cases cured noninvasively or invasively and the patients were discharged without any complications.

\section{Discussion}

In case 1 and 2, intravenous sedation kept optimal sedation status. But when an operation with the pain started, sedation status decreasing and patient's body movement were observed. Local anesthetic was added many times, but body movement and hemodynamics changes were observed. It was considered that local anesthesia was not enough for pain of intramaxillary fixation. In addition, pentazocine was administrated when patient's body movement and complaints of pain were observed in case 1 . But, body movement restraint became more difficult. This is caused by increase sedation and insufficient analgesia, because pentazocine has $\kappa$ receptor action that act on analgesia and sedation [8]. Therefore, in operation for intramaxillary fixation, only with local anesthetic and pentazocine, enough analgesia is not provided.

In case 3 and 4 , fentanyl was administrated, and patient's body movement and hemodynamics changes were not observed. In case 


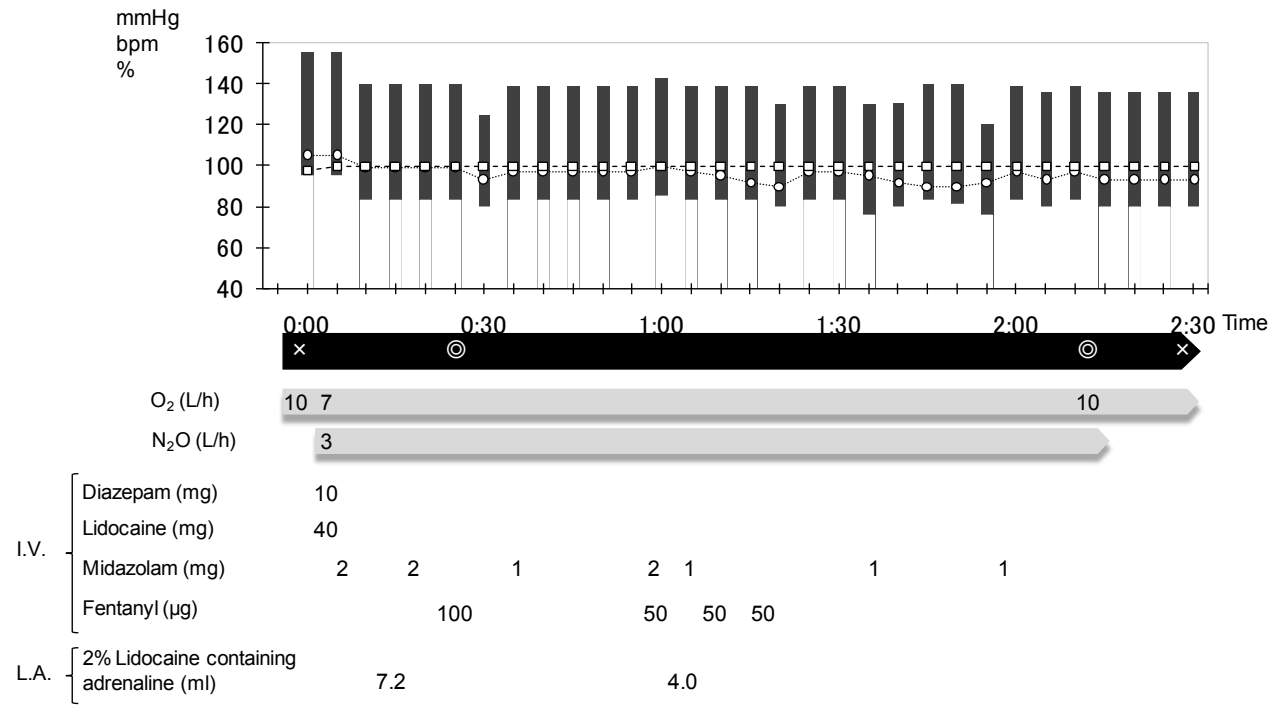

Figure 4. Anesthesia record in case 4

Anesthesia time: 2 hours 25 minutes, Operation time 1 hour 47 minutes.

4, sedative and analgesic were administrated based on concept by balanced anesthesia. In "balanced anesthesia" of general anesthesia, anesthesiologists have disassociated 3 components of anesthesia, i.e., unconsciousness (sedation), analgesia, and immobility (muscle relaxation), which are independently controlled with a sedative, an analgesic, and a muscle relaxant, respectively [9]. Thus, in "balanced anesthesia" of intravenous sedation, anesthesiologists have disassociated 2 components of anesthesia, i.e., sedation and analgesia, which are independently controlled with a sedative and an analgesic, respectively. Specifically, intravenous sedation based on concept of balanced anesthesia was to administrate fentanyl that is analgesic in addition to sedative. Fentanyl has strong analgesic effect that is hundredfold more powerful than morphine. By contrast, pentazocine is one third of morphine [8]. In addition, fentanyl does not cause hypersedation such as the pentazocine because $\mu$ receptor action of fentanyl has little sedative action [10,11]. Furthermore, in fentanyl, effect concentration with analgesia effect and without respiratory depression was approximately $1-2 \mathrm{ng} / \mathrm{ml}$. Modeled fentanyl plasma concentrations are easily measured by being accompanied by pharmacokinetic simulation $[8,12-14]$. Therefore, fentanyl infusion used in conjunction with pharmacokinetic simulation and monitoring of oxygen saturation and respiratory rate is safety.

However, fentanyl may also cause muscle rigidity by chest wall rigidity and glottis closure. In that case, muscle rigidity is improved by opioid antagonist and muscle relaxant [15-19] and, airway management such as trachea intubation may be required. Hence, the quantity of mouth opening was gauged before intravenous sedation. And, on the day after intramaxillary fixation, intermaxillary fixation was performed. Therefore, opioid combined sedation with preoperative consultation, respiratory monitoring and pharmacokinetic simulation is able to perform safely.

\section{Conclusion}

In local anesthesia only, analgesia effect is insufficient for pain of intramaxillary fixation. In intravenous sedation for intramaxillary fixation operation, the full agonist opioid such as the fentanyl, specialized in analgesia, is useful to provide enough analgesia. Fentanyl combined sedation based on concept of balanced anesthesia is effective for intramaxillary fixation.

\section{Acknowledgments}

This work was presented, in part, on October 19-21, 2012, at the Annual meeting of the Japanese Society for Oral and Maxillofacial Surgery, Minato-mirai, Yokohama.

I would like to thank Drs. George Sekine, Hiroaki Ishibashi, Yoshiki Nariai, Takahiro Kanno and Takayuki Kato, for they helped with above presentation.

\section{References}

1. Ouchi K, Sugiyama K (2015) Required propofol dose for anesthesia and time to emerge are affected by the use of antiepileptics: prospective cohort study.BMC Anesthesiol 15: 34. [Crossref]

2. Stassen LF, O'Halloran M (2011) Functional surgery of the temporomandibular join with conscious sedation for "closed lock" using eminectomy as a treatment: a case series.J Oral Maxillofac Surg 69: e42-49. [Crossref]

3. Stavropoulos F, Abramowicz S (2008) Management of the oral surgery patient diagnosed with epidermolysis bullosa: report of 3 cases and review of the literature. $J$ Oral Maxillofac Surg 66: 554-559. [Crossref]

4. Taguchi T, Fukuda K, Sekine H, Kakizawa T (2011) Intravenous sedation and hemodynamic changes during dental implant surgery.Int J Oral Maxillofac Implants 26: 1303-1308. [Crossref]

5. Ouchi K, Fujiwara S, Sugiyama K (2016) Acoustic method respiratory rate monitoring is useful in patients under intravenous anesthesia.J Clin Monit Comput. [Crossref]

6. Ettinger KS, Jacob AK, Viozzi CF, Van Ess JM, Fillmore WJ, Arce K (2015) Does Intravenous Midazolam Dose Influence the Duration of Recovery Room Stay Following Outpatient Third Molar Surgery? J Oral Maxillofac Surg. 73:2287-2293. [Crossref]

7. Nirwan AS, Jain N, Pragasm M, Kamblimath D, Bhargava A, et al. (2014) Randomised Comparative Study on Propofol and Diazepam as a Sedating Agent in Day Care Surgery.J Maxillofac Oral Surg 13: 583-591. [Crossref]

8. Fukuda K. Opioids (2005) In: Miller RD, editor. Miller's Anesthesia. 7th Edition. Philadelphia: ELSEVIER 769-824.

9. Kurata J (2010) Deep hypnosis as a sign of "imbalance" in balanced anesthesia.Anesth Analg 110: 663-665. [Crossref]

10. Katoh T, Uchiyama T, Ikeda K (1994) Effect of fentanyl on awakening concentration of sevoflurane.Br J Anaesth 73: 322-325. [Crossref] 
11. Iwakiri H, Nagata O, Matsukawa T, Ozaki M, Sessler DI (2003) Effect-site concentration of propofol for recovery of consciousness is virtually independent of fentanyl effect-site concentration.Anesth Analg 96: 1651-1655. [Crossref]

12. Shafer SL, Varvel JR, Aziz N, Scott JC (1990) Pharmacokinetics of fentanyl administered by computer-controlled infusion pump. Anesthesiology. 73:1091-1102 [Crossref]

13. Ouchi K, Ohara S, Sunada K, Nagata O. (2008) [The experience of stabilized circulatory dynamics in total intravenous anesthesia by changing analgesic to remifentanil from fentanyl]. J Clin Anesth (Jpn)32:782-784.

14. Kaneda K, Han TH (2009) Comparative population pharmacokinetics of fentanyl using non-linear mixed effect modeling: burns vs. non-burns.Burns 35: 790-797. [Crossref]

15. Abrams JT, Horrow JC, Bennett JA, Van Riper DF, Storella RJ (1996) Upper airway closure: a primary source of difficult ventilation with sufentanil induction of anesthesia Anesth Analg. 83:629-632. [Crossref]

16. Ackerman WE, Phero JC, Theodore GT (1990) Ineffective ventilation during conscious sedation due to chest wall rigidity after intravenous midazolam and fentanyl. Anesth Prog. 37:46-48. [Crossref]

17. Bennett JA, Abrams JT, Van Riper DF, Horrow JC (1997) Difficult or impossible ventilation after sufentanil-induced anesthesia is caused primarily by vocal cord closure.Anesthesiology 87: 1070-1074. [Crossref]

18. Comstock MK, Carter JG, Moyers JR, Stevens WC (1981) Rigidity and hypercarbia associated with high dose fentanyl induction of anesthesia.Anesth Analg60: 362-363. [Crossref]

19. Ouchi K, Uno H, Sugiyama K (2012) [The effect of priming with rocuronium on prevention of remifentanil mediated difficult ventilation]. J Clin Anesth (Jpn). 36:16011606.

Copyright: @2016 Ouchi K. This is an open-access article distributed under the terms of the Creative Commons Attribution License, which permits unrestricted use, distribution, and reproduction in any medium, provided the original author and source are credited. 